\title{
MODELO CALGARY NA AVALIAÇÃOESTRUTURAL, DESENVOLVIMENTAL E FUNCIONALDA FAMÍLIA DE MULHERES MASTECTOMIZADAS APÓS CÂNCER DE MAMA
}

Patrícia Peres de Oliveira ${ }^{1}$, Lorena Nogueira Maia², Mariella de Souza Resende², Rúbia Sousa Macedo², Andrea Bezerra Rodrigues ${ }^{3}$, Maria Ísis Freire de Aguiar ${ }^{3}$

${ }^{1}$ Enfermeira. Doutora em Enfermagem. Docente da Universidade Federal de São João del-Rei. Divinópolis, MG, Brasil. ${ }^{2}$ Discente de Enfermagem. Universidade Federal de São João del-Rei. Divinópolis, MG, Brasil.

${ }^{3}$ Enfermeira. Doutora em Enfermagem. Docente da Universidade Federal do Ceará. Fortaleza, CE, Brasil.

RESUMO: Objetivou-se avaliar a estrutura, o desenvolvimento e a funcionalidade da família de mulheres com câncer de mama submetidas à mastectomia. Trata-se de um estudo qualitativo em que foi utilizado como referencial teórico o Modelo Calgary de avaliação familiar e como estratégia metodológica o estudo de caso. Os dados foram coletados junto a duas famílias, no período de maio a setembro de 2014, por meio de instrumento pré-elaborado. Verificou-se que uma família era nuclear, formada pelo casal e suas três filhas, a outra família era estendida, constituída por duas irmãs, ambas mastectomizadas e seus respectivos filhos. A aplicação do modelo de avaliação familiar permitiu conhecer aspectos relacionados à estrutura, ao funcionamento e ao desenvolvimento das duas famílias, que interferem, dificultam ou favorecem o desenvolvimento do cuidado no cotidiano. Conclui-se que este estudo possibilitou a realização da abordagem familiar que pode interferir, dificultar ou favorecer o desenvolvimento do cuidado no dia-a-dia.

DESCRITORES: Família; Neoplasias; Enfermagem; Saúde da mulher.

\section{USE OF THE CALGARY FAMILY ASSESSMENT MODEL IN STRUCTURAL, DEVELOPMENTAL AND FUNCTIONAL ASSESSMENT OF THE FAMILY OF MASTECTOMIZED WOMEN WITH BREAST CANCER}

\begin{abstract}
The present study aimed to assess the structure, development and functionality of the family of women with breast cancer who underwent mastectomy. It is a qualitative study based on the Calgary Family Assessment Model and case study methodology was used. The data were collected from two families in May-September 2014, through a previously designed instrument. One of the families was a nuclear family formed by the biological parents and their three daughters, and the other family was extended, consisting of two sisters, both mastectomized, and their respective children. The use of the family assessment model provided knowledge on aspects related to the structure, functioning and development of the two families that interfere, impair or favor the adequate provision of daily care.In conclusion, this study made it possible to use a family assessment model that can interfere, impair or favor the adequate provision of daily care to the patients.
\end{abstract}

DESCRIPTORS: Family; Neoplasias; Nursing; Women's health.

\section{MODELO CALGARY EN LA EVALUACIÓN ESTRUCTURAL, DE DESARROLLO Y FUNCIONAL DE LA FAMILIA DE MUJERES MASTECTOMIZADAS POS CÁNCER DE MAMA}

RESUMEN: El objetivo fue evaluar la estructura, el desarrollo y la funcionalidad de la familia de mujeres con cáncer de mama sometidas a la mastectomía. Es un estudio cualitativo en que fue utilizado como referencial teórico el Modelo Calgary de evaluación familiar y como estrategia metodológica el estudio de caso. Los datos fueron obtenidos con dos familias, en el periodo de mayo a septiembre de 2014, por medio de instrumento preelaborado. Se ha verificado que una familia era nuclear, formada por la pareja y sus tres hijas, la otra familia era ampliada, constituida por dos hermanas, ambas mastectomizadas y sus respectivos hijos. La aplicación del modelo de evaluación familiar permitió conocer aspectos relacionados a la estructura, al funcionamiento y al desarrollo de las dos familias, los cuales interfieren, dificultan o favorecen el desarrollo del cuidado en el cotidiano. Se concluye que este estudio posibilitó la realización del abordaje familiar que puede interferir, dificultar o favorecer el desarrollo del cuidado en el día a día. DESCRIPTORES: Familia; Neoplasias; Enfermería; Salud de la Mujer. 


\section{INTRODUÇÃO}

A estrutura familiar se firma mais sobre as relações emocionais e sociais, a quem os indivíduos recorrem em momentos de necessidade e, principalmente, compartilham os momentos de alegria, do que sobre as relações de parentesco. Enfim, o que firma um grupo de pessoas como família é a relação de apoio: emocional, educacional, financeiro ou social entre seus membros ${ }^{(1-2)}$.

A família, geralmente, não está preparada para enfrentar o adoecimento e para suportar o sofrimento de seu familiar, contribuindo para que este processo se torne mais sofrido para as mulheres que adoecem ${ }^{(2)}$. No caso de diagnóstico de câncer de mama, o efeito é ainda mais devastador na vida da pessoa que o recebe e de seus familiares, pelo temor às mutilações, os possíveis efeitos colaterais advindos dos tratamentos, o medo da morte, e o impacto material, social e emocional que quase sempre ocorrem $^{(3)}$.

É indiscutível o papel social que a família exerce na vida destas mulheres, oferecendo apoio, ajudando-as a suportar o diagnóstico da doença e a superar seus transtornos, garantindo desta forma uma vida mais ajustada, menos estressante e com perspectivas de cura ${ }^{(4-5)}$.

Sendo o câncer de mama uma doença crônica, o tratamento será ao longo da vida e, para que seja bem sucedido, os familiares, desde a ocasião da descoberta, precisarão conhecer as possíveis alterações advindas dos tratamentos, os sinais das complicações, bem como atuar de forma assertiva nas possíveis intercorrências ${ }^{(5)}$. Dessa maneira, a comoção que a doença oncológica causa na família e as formas de enfrentamento são particulares de cada família, pois possuem crenças, valores, histórias e rotinas diferentes ${ }^{(4-5)}$.

Os profissionais de saúde, com base nas informações obtidas, precisam usar seus conhecimentos sobre cada família a fim de assegurar atendimento holístico, de forma a relacionar fatores biológicos, sociais e espirituais, elaborando a partir disso a melhor assistência ${ }^{(1,3)}$.

Diante deste contexto, optou-se por utilizar o Modelo Calgary de Avaliação da Família (MCAF), que permite um espectro expandido da família, incluindo suas relações internas e externas, fragilidades e fortalezas.

O MCAF é uma estrutura multidimensional formada por três categorias fundamentais: estrutural, desenvolvimental, funcional e suas múltiplas subcategorias ${ }^{(6)}$ que permitem juntar elementos para dar subsídio e direcionar o cuidado com a família ${ }^{(1,6)}$. O seu uso promove o entendimento da dinâmica e funcionamento familiar de forma interacional, e isto, por sua vez, proporciona a avaliação de seus elementos e a observação de mudanças em sua dinâmica ${ }^{(2,6-7)}$.

A abordagem dos sistemas familiares tem sido usada para assessorar na compreensão da família como unidade de cuidado e não apenas como a somatória da individualidade de cada elemento da família, em diferentes contextos ${ }^{(2-3)}$.

No Brasil, o MCAF tem sido pouco utilizado em famílias de adultos com neoplasia, sendo mais empregado em pesquisas com crianças, adolescentes, idosos e na área de saúde mental. A utilização deste modelo permite ao enfermeiro conhecer a família em seu contexto e identificar suas necessidades, bem como alternativas de cuidado específicas a sua condição.

A motivação desta pesquisa decorre por se tratar de tema da maior importância, uma doença que requer cuidado embasado em muito conhecimento e delicadeza devido ao caráter do "irreversível", assim surgiu o interesse de conhecer a dinâmica cotidiana de famílias de mulheres com câncer de mama que sofreram mastectomia.

Apoiadas nessas considerações, surgiram os seguintes questionamentos: como é a estrutura e o funcionamento da família de mulheres com câncer de mama submetidas à mastectomia? Qual o vínculo afetivo entre os membros dessas famílias? Para respondê-las, determinamos como objetivo do estudo avaliar a estrutura, o desenvolvimento e a funcionalidade da família de mulheres com câncer de mama submetida à mastectomia.

\section{REFERENCIAL TEÓRICO}

\section{Modelo Calgary de Avaliação Familiar}

Versa-se de um modelo multiestrutural, aprovado em todo o mundo e referenciado em cursos de enfermagem ${ }^{(6)}$. Tem como meta avaliar a família e adquirir informações, habilidades e conhecimentos para plausíveis intervenções imperativas. Envolve os conceitos de sistema, comunicação, mudança e cibernética, sendo composto por três categorias fundamentais: estrutural, de desenvolvimento e funcional ${ }^{(1-3,6)}$.

É função de cada enfermeiro selecionar as 
subcategorias desse modelo a serem exploradas. Deste modo, nem todas as subcategorias são avaliadas em um primeiro encontro, e algumas podem nunca ser exploradas ${ }^{(2,6-7)}$.

A categoria estrutural abrange a estrutura da família, ou seja, quem faz parte dela, qual é o vínculo afetivo entre seus elementos em comparação com as pessoas de fora, e qual é o seu contexto $^{(2,6)}$. Três aspectos da estrutura familiar podem ser determinados: estrutura interna (composição da família, gênero, orientação sexual, ordem de nascimento, subsistemas e limites), estrutura externa (família extensa, informações sobre a origem e procriação da família e sistemas mais amplos, que se referem a diferentes estabelecimentos sociais e pessoas com os quais a família tem certo contato e que laboram como apoios pontuais) e contexto (etnia, raça, classe social, espiritualidade/religião e ambiente $)^{(6)}$.

Empregam-se dois instrumentos para esquematizar as estruturas internas e externas da família: o genograma e o ecomapa ${ }^{(1-2,6)}$. O genograma é uma representação gráfica da estrutura familiar interna. O escopo fundamental do genograma é assessorar na avaliação, planejamento e intervenção familiar ${ }^{(6)}$. Na sua elaboração são empregados símbolos e códigos que seguem um padrão; e assim que pronto, permite verificar de forma clara quais membros compõem a família e, deste modo, providencia bases para a análise e discussão das interações familiares(7). Propicia também que a própria família identifique quais elementos a integram e as relações estabelecidas entre esses membros ${ }^{(6-7)}$.

O ecomapa é um diagrama das relações viventes ou não entre a comunidade e a família, e permite estimar apoios sociais e as redes disponíveis, além da utilização destes pela família $(1,6)$. O ecomapa é dinâmico, uma vez que representa a presença ou a ausência de recursos econômicos, sociais e culturais, em certo período do ciclo vital da família, os quais podem ser modificados ao longo do tempo ${ }^{(6-7)}$.

A categoria de desenvolvimento faz referência à mudança progressiva da história da família durante as fases do ciclo de vida: sua história, o fluxo de vida, o crescimento da família, o nascimento e a morte ${ }^{(2)}$.

Em relação à categoria funcional, refere-se à maneira como as pessoas da família interagem. Pode ser explorado o aspecto do funcionamento instrumental, que está relacionado às atividades da vida diária, e o aspecto do funcionamento expressivo, referente a modos de comunicação, solução de problemas, crenças, papéis, regras e alianças ${ }^{(2,6)}$.

Acredita-se que, ao considerar a família da mulher com câncer de mama que vivenciou a mastectomia como um sistema, isso contribuirá para a sustentação da operacionalização de uma avaliação familiar integral, que reconheça a sua estrutura, o desenvolvimento de suas tarefas e de seus vínculos no decorrer do ciclo de vida e o funcionamento de suas atividades e estilos de comunicação.

Dentro desse ponto de vista, a dinâmica familiar influencia o desenvolvimento da mulher, sua situação ao passar pelo tratamento de câncer de mama e ser mastectomizada e esta por sua vez, influencia a dinâmica do grupo familiar, continuamente.

\section{MÉTODO}

Visando atingir o objetivo traçado, adotouse como estratégia metodológica da abordagem qualitativa o estudo de $\mathrm{caso}^{(8)}$, método amplo que permite ser aplicado a uma variedade de problemas e pode ser utilizado em diversas áreas de pesquisa para proporcionar maior conhecimento e envolvimento do pesquisador com uma situação real observada. Como referencial teórico foi utilizado o MCAF.

O estudo foi realizado por meio de quatro encontros com as duas famílias estudadas. A família estendida foi constituída por duas irmãs e seus respectivos filhos homens, as duas mulheres foram submetidas ao procedimento e tratamento para a neoplasia de mama. A outra família era nuclear, formada pelo casal e suas três filhas.

A primeira entrevista teve por objetivo apresentar os aspectos éticos e legais para realização da pesquisa e convidá-los a participarem da mesma. Na segunda visita foi construído o genograma e o ecomapa com a participação da família. Na terceira e quarta visitas, foram realizadas discussões e considerações sobre o genograma e o ecomapa e orientações específicas para cada situação vivenciada pela família.

O cenário de estudo foi o domicílio das famílias das mulheres que passaram pelo tratamento de câncer de mama e foram mastectomizadas, moradoras de um município do estado de Minas Gerais. Foram realizadas visitas domiciliares nos meses de maio a setembro de 2014.

Com base em amostragem por conveniência, 
adotaram-se como critérios de inclusão: famílias com pelo menos uma mulher que tivesse passado por tratamento de câncer de mama e mastectomia, moradoras de um município do estado de Minas Gerais, cenário da pesquisa, e cadastradas em uma entidade filantrópica, sem fins lucrativos.

Os critérios de exclusão foram: famílias de mulheres mastectomizadas sem endereço e/ ou telefones no cadastro, sem disponibilidade pessoal para entrevistas nas visitas domiciliares e incapacidade de compreender e/ou responder as entrevistas.

Os participantes foram sete integrantes de duas famílias que desejaram ser incluídos na pesquisa. As três mulheres das duas famílias encontravamse em terapia adjuvante com tamoxifeno, um modulador seletivo do receptor de estrógeno oral, utilizado no tratamento do câncer de mama.

Ressalta-se que, embora nem todos os integrantes das famílias tenham participado da pesquisa, o enfoque foi a unidade familiar. Dessa forma, todos os participantes foram convidados a observar sua família, conforme preconiza o referencial $\mathrm{MCAF}^{(6)}$.

Utilizou-se o instrumento do $\mathrm{MCAF}^{(6)}$, composto por perguntas abertas, enfocando a avaliação estrutural da família (com a construção do genograma e do ecomapa), a avaliação do desenvolvimento da família ao longo do ciclo vital com suas tarefas e vínculos, e a avaliação do funcionamento instrumental (atividades da vida diária) e expressivo (estilos de comunicação, papéis, influência, crenças, alianças da família).

A construção do genograma e do ecomapa foi realizada com a participação da família, com liberdade para discussões e considerações sobre os diagramas, além das orientações específicas para cada situação vivenciada. O desenvolvimento do estudo ocorreu em conformidade com os preceitos éticos e o projeto foi aprovado pelo Comitê de Ética e Pesquisa da Universidade Federal de São João del-Rei, conforme CAAE: 28929914.5.0000.5545 e protocolo número 620.273. Para preservar a identidade dos membros das famílias participantes, usaram-se nomes fictícios da flora.

\section{RESULTADOS}

A família um era composta por Cravo e Margarida e suas três filhas Orquídea, Romã e Bromélia, conforme Figura 1.

$\mathrm{Na}$ avaliação estrutural da família Um, foi identificada que ela é do tipo nuclear. Margarida, que fez mastectomia total, quimioterapia e radioterapia em 2012, trabalha como manicure e reside em casa própria. Ela e mais oito irmãos são fruto de um relacionamento de 56 anos; seu pai (Girassol) mora sozinho próximo de sua casa e necessita de seus cuidados e das suas filhas, devido a não saber cozinhar e apresentar falhas na memória. Sua mãe (Rosa) faleceu com 69 anos vítima de câncer de mama metastático, dois meses após o diagnóstico e início do tratamento para câncer de mama de Margarida. Cravo, marido de Margarida, tem 44 anos e trabalha como vigilante em um banco privado. O casal teve três filhas, cujas idades são 17, 14 e 8 anos, todas frequentam a escola e, Orquídea, a filha mais velha, além de estudar no período noturno, trabalha em um comércio de roupas.

O vínculo afetivo entre eles é muito forte, como verificado na Figura 2.

Em relação à categoria desenvolvimental, identificamos que Margarida é a única que necessita de fazer acompanhamento de saúde na entidade filantrópica localizada na cidade onde reside, sem fins lucrativos, cujo objetivo é prestar assistência a pessoas com neoplasias e na Unidade Básica de Saúde próxima de sua residência. Afirma que segue corretamente todas as orientações dos profissionais de saúde quanto aos cuidados para sua condição atual e que ambos os atendimentos são de excelente qualidade.

Faz uso diário de tamoxifeno e eventualmente utiliza alguns analgésicos para dor na coluna. Renda familiar de seis salários mínimos, realizam atividades diversificadas para melhorar a qualidade de vida, como por exemplo, Margarida realiza fisioterapia (Reeducação Postural Global) e todos os membros da família caminham diariamente. Nos últimos dois anos, frequentou um hospital em Belo Horizonte, Minas Gerais, para realização inicial de sessões de quimioterapia seguidas de radioterapia, e após mastectomia total. Durante as visitas domiciliares, queixouse do calor que começou a sentir após início do uso do tamoxifeno. Apesar de todo encargo com seu pai e medo de morrer e deixar suas filhas, consegue manter boa qualidade de vida. Os outros membros da família relataram não ter doenças. A família utiliza exclusivamente o Sistema Único de Saúde.

Por meio da avaliação da categoria funcional, foi identificado que Margarida é amiga e parceira do seu companheiro, com quem é casada há 22 anos. A relação com o marido é de afeto, ajuda 


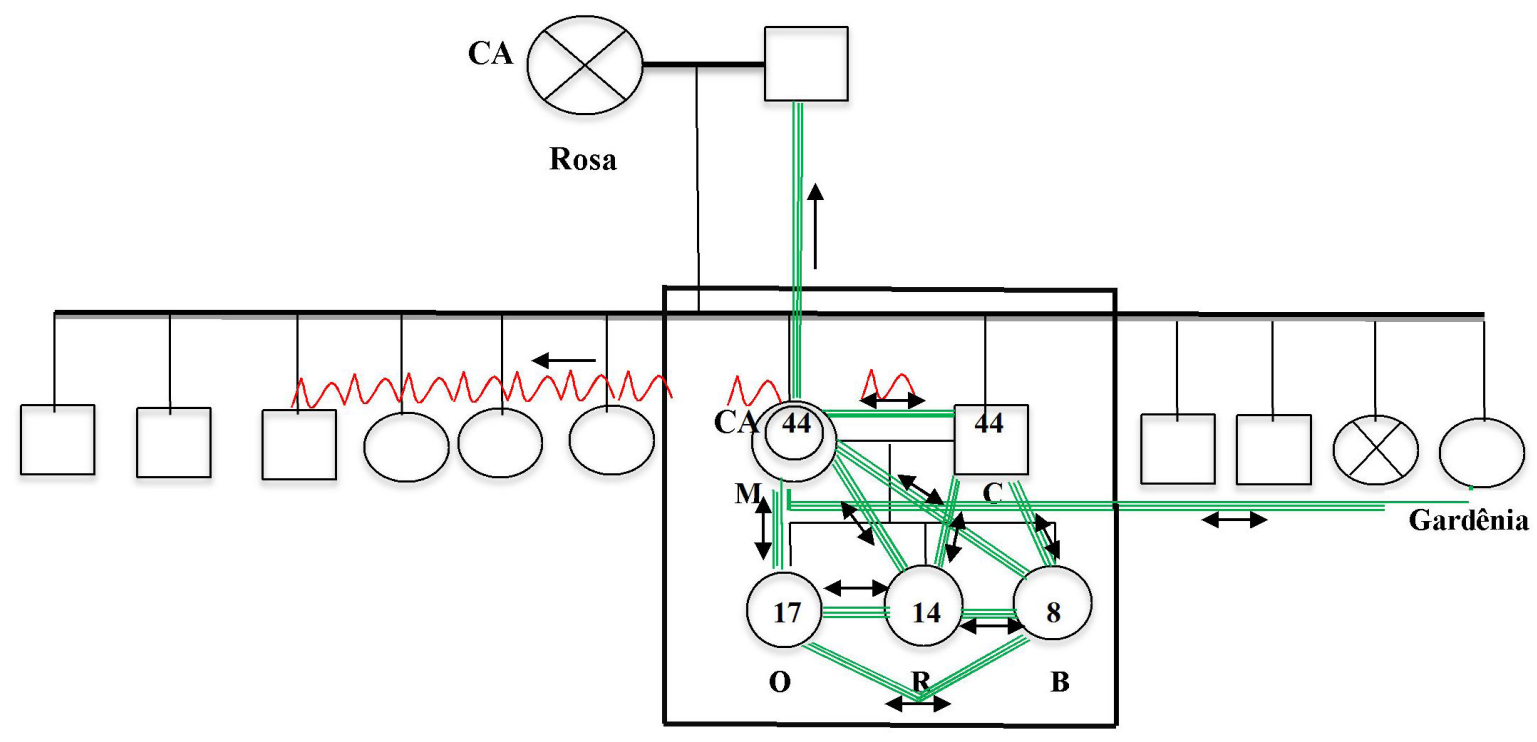

\begin{tabular}{|c|c|c|c|c|c|c|c|c|c|}
\hline \multicolumn{2}{|c|}{ LEGENDA } & $\bar{\equiv}$ & Vínculo & $\square 0$ & Casamento & $\square 0$ & Moram & \multirow[t]{3}{*}{$M$} & \multirow[t]{3}{*}{ Conflito } \\
\hline$\square$ & Homem & & muito forte & & & & juntos & & \\
\hline 0 & Mulher & $\nabla \otimes$ & Óbito & (2) & Pessoa índice & CA & Câncer & & \\
\hline $\mathbf{M}$ & Margarida & C & Cravo & $\mathbf{0}$ & Orquídea & $\mathbf{R}$ & Romã & B & Bromélia \\
\hline
\end{tabular}

Figura 1 - Genograma da família 1. Divinópolis, 2014

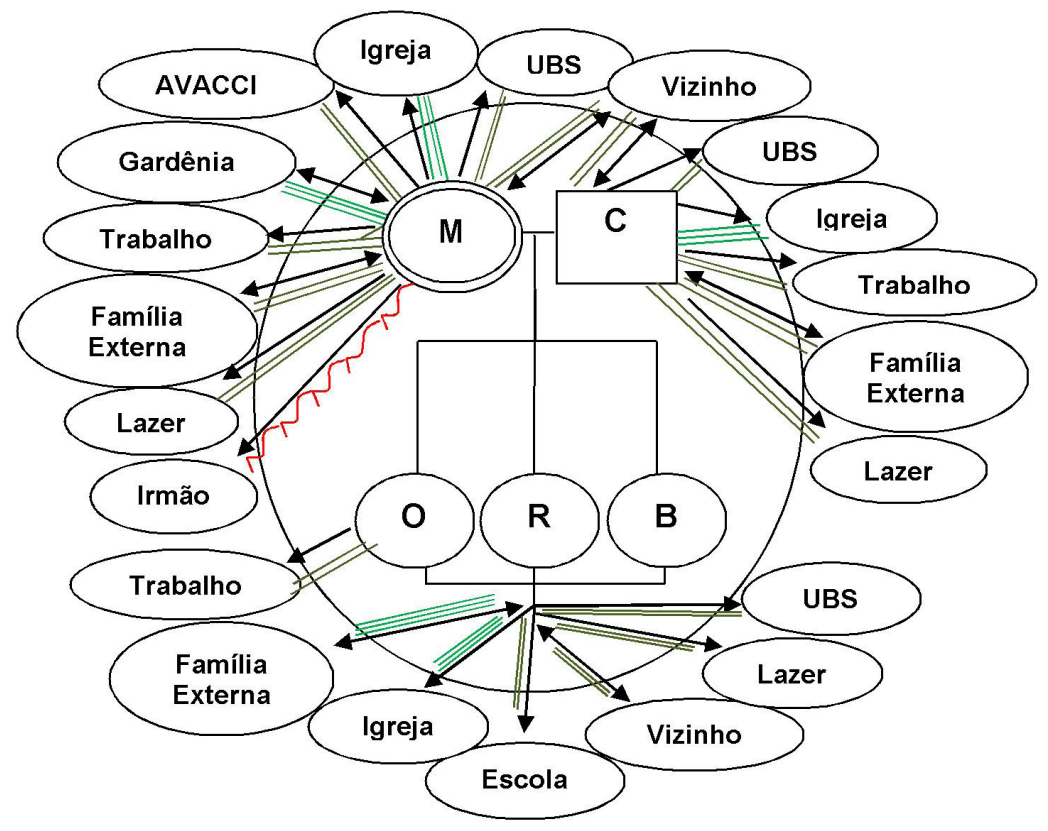

\begin{tabular}{|c|c|c|c|c|c|c|c|c|c|}
\hline \multicolumn{2}{|c|}{ LEGENDA } & \multirow{3}{*}{ AVACCI } & \multirow{3}{*}{$\begin{array}{l}\text { Associação de } \\
\text { Voluntariados } \\
\text { no Apoio ao } \\
\text { Combate ao } \\
\text { Câncer }\end{array}$} & & \multirow{2}{*}{$\begin{array}{l}\begin{array}{l}\text { Vínculo } \\
\text { moderado }\end{array} \\
\text { Vínculo } \\
\text { forte }\end{array}$} & \multirow{2}{*}{$\begin{array}{l}\mathbf{M} \\
\mathbf{C}\end{array}$} & \multirow{2}{*}{$\begin{array}{l}\text { Margarida } \\
\text { Cravo }\end{array}$} & \multirow{2}{*}{$\begin{array}{l}\mathbf{R} \\
\mathbf{B}\end{array}$} & \multirow{2}{*}{$\begin{array}{l}\text { Romã } \\
\text { Bromélia }\end{array}$} \\
\hline$\rightarrow$ & $\begin{array}{l}\text { Fluxo de } \\
\text { energia }\end{array}$ & & & 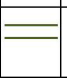 & & & & & \\
\hline UBS & $\begin{array}{l}\text { Unidade } \\
\text { Básica de } \\
\text { Saúde }\end{array}$ & & & $=$ & $\begin{array}{l}\text { Vínculo } \\
\text { muito forte }\end{array}$ & $\mathbf{O}$ & Orquídea & & \\
\hline
\end{tabular}

Figura 2 - Ecomapa da família 1. Divinópolis, 2014 
mútua e preocupação de um para com o outro. Em seus relatos, demonstra sempre de maneira carinhosa e afetiva ter um bom relacionamento com as três filhas. No entanto, em alguns momentos relatou existir relação conflituosa com um de seus irmãos, que reside próximo e faz uso exacerbado de bebida alcoólica. Nestes momentos de estresse, Margarida procura sua irmã mais nova (Gardênia) com quem mantém uma forte relação, entretanto, verificou-se que se relaciona muito bem com todos os irmãos e com os familiares do marido. As filhas, em entrevista com as pesquisadoras, afirmaram terem medo de a mãe vir a falecer, com um retorno do câncer, como aconteceu com a avó materna.

É uma família dinâmica, sempre participam de atividades de lazer juntos e com amigos, tais como caminhadas diárias, bingos e reuniões sociais que realizam em sua residência. Durante os encontros, todos os membros demonstraram ter uma relação forte com Deus, são evangélicos, frequentam juntos os cultos aos domingos. Margarida inclusive disse que Deus é seu confidente espiritual para todos os momentos, tantos os de alegria como os de tristeza.

Ao ser questionada sobre o conceito de saúde e às mudanças ocorridas em sua vida, Margarida relatou que para ela saúde é ter disposição e animação para realizar todas as suas atividades, e que sempre reage muito bem às mudanças ocorridas em sua vida, procurando enfrentar e superar, sejam elas positivas ou negativas. Ressaltou ainda a importância da presença de familiares e amigos durante o seu tratamento, por meio do incentivo, apoio, carinho e solidariedade demonstrada.

A família Dois, representada na Figura 3, era composta por duas irmãs, Araucária (50 anos) e Camélia (48 anos), e seus respectivos filhos, Hibisco com 28 anos e Jacinto com 17 anos de idade.

$\mathrm{Na}$ avaliação estrutural da família Dois, foi identificado que ela é do tipo estendida. Moravam em uma casa que é de propriedade de seu irmão mais velho, não pagam aluguel. Elas e mais sete irmãos são fruto do relacionamento de seus pais; ambos falecidos. Araucária é a quarta filha e Camélia a quinta. Hibisco, filho de Araucária, é educador físico e trabalha em duas academias de ginástica. Jacinto, com 17 anos, estuda à noite no terceiro ano do segundo grau e trabalha em uma copiadora. Os vínculos afetivos entre mãefilho, tia-sobrinho e primos são fortes. Já as irmãs têm divergências de opinião a todo momento, confirmado pelos seus filhos. O genograma e o ecomapa apresentado foram construídos junto às irmãs e seus filhos. A mais velha delas é viúva, já a mais nova é divorciada. Em relação à categoria desenvolvimental, identificamos que Araucária e Camélia, atualmente fazem uso de tamoxifeno diário, como verificado na Figura 4.

No final do ano de 2009, Araucária apresentou sintomatologia de câncer de mama e foi submetida à mastectomia total e quimioterapia. Em junho de 2010, Camélia foi diagnosticada com câncer de mama, sendo submetida à quimioterapia, radioterapia e mastectomia total. Ambas fizeram tratamento em um hospital da rede pública localizado em Belo Horizonte, estado de Minas Gerais.

Atualmente ambas fazem acompanhamento de saúde na entidade filantrópica localizada na cidade onde residem, sem fins lucrativos, cujo objetivo é prestar assistência a pessoas com neoplasias, e na Unidade Básica de Saúde próxima de sua residência. Afirmam que seguem corretamente todas as orientações dos profissionais de saúde quanto aos cuidados para sua condição atual e que ambos os atendimentos são de excelente qualidade. A renda salarial mensal da família é de sete salários mínimos. Araucária demonstra mais otimismo e animação, faz caminhadas diariamente e viaja pelo menos uma vez por mês com amigas. Já Camélia é tímida e não gosta de sair de casa, prefere ver televisão e ouvir rádio.

Por meio da avaliação da categoria funcional, foi identificado que as irmãs desempenham o papel de mãe, pai, dona de casa, amiga e parceira dos seus filhos e sobrinhos. No entanto, em muitos momentos relataram existir relação conflituosa entre as irmãs devido à diferença na personalidade e modo de viver a vida. Nos momentos de estresse procuram a irmã caçula (Dália) com quem mantêm uma forte relação e é uma referência para toda a família desde a morte de seus pais.

O impacto do câncer na vida de Camélia parece ter sido grande, pois afirmou ter medo de metástases e muitas vezes ficar pensativa e chorosa. Já Araucária demonstrou otimismo e adaptação às limitações impostas pela doença, reage bem às mudanças ocorridas em sua vida, procurando enfrentar e superar, sejam elas positivas ou negativas, inclusive passou a ter um novo estilo de vida, mais ativo após o término do tratamento quimioterápico. Relataram receber apoio e incentivo de todos os familiares, vizinhos e amigos. 


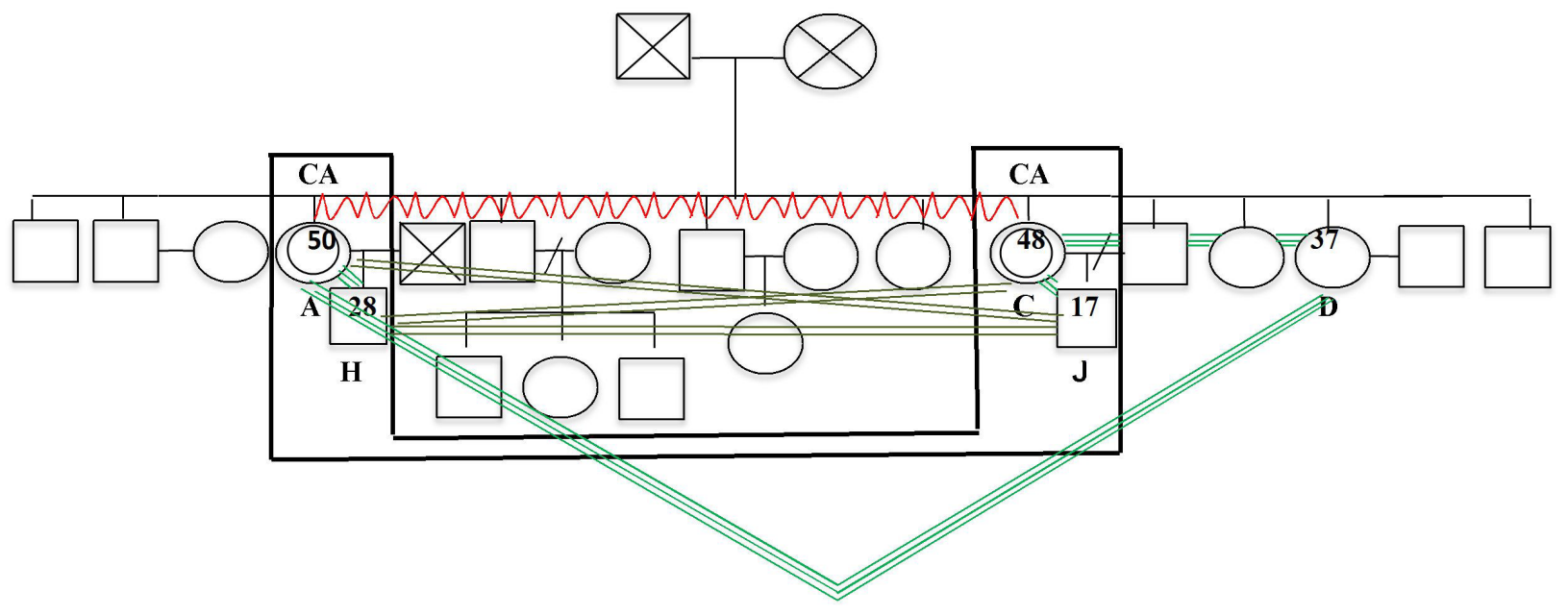

\begin{tabular}{|c|c|c|c|c|c|c|c|c|c|}
\hline \multicolumn{2}{|c|}{ LEGENDA } & $\equiv$ & Vínculo & $\square 0$ & Casamento & $﹎{1} 0$ & Moram & ㅁ, & Separação \\
\hline$\square$ & Homem & $=$ & $\begin{array}{l}\text { Vínculo } \\
\text { forte }\end{array}$ & & & & & & \\
\hline $\mathrm{O}$ & Mulher & $\nabla \otimes$ & Óbito & () & $\begin{array}{l}\text { Pessoa } \\
\text { indice }\end{array}$ & CA & Câncer & $M$ & Conflito \\
\hline $\mathbf{A}$ & Araucária & $\mathrm{H}$ & Hibisco & C & Camélia & $\mathbf{J}$ & Jacinto & D & Dália \\
\hline
\end{tabular}

Figura 3 - Genograma da Família 2. Divinópolis, 2014

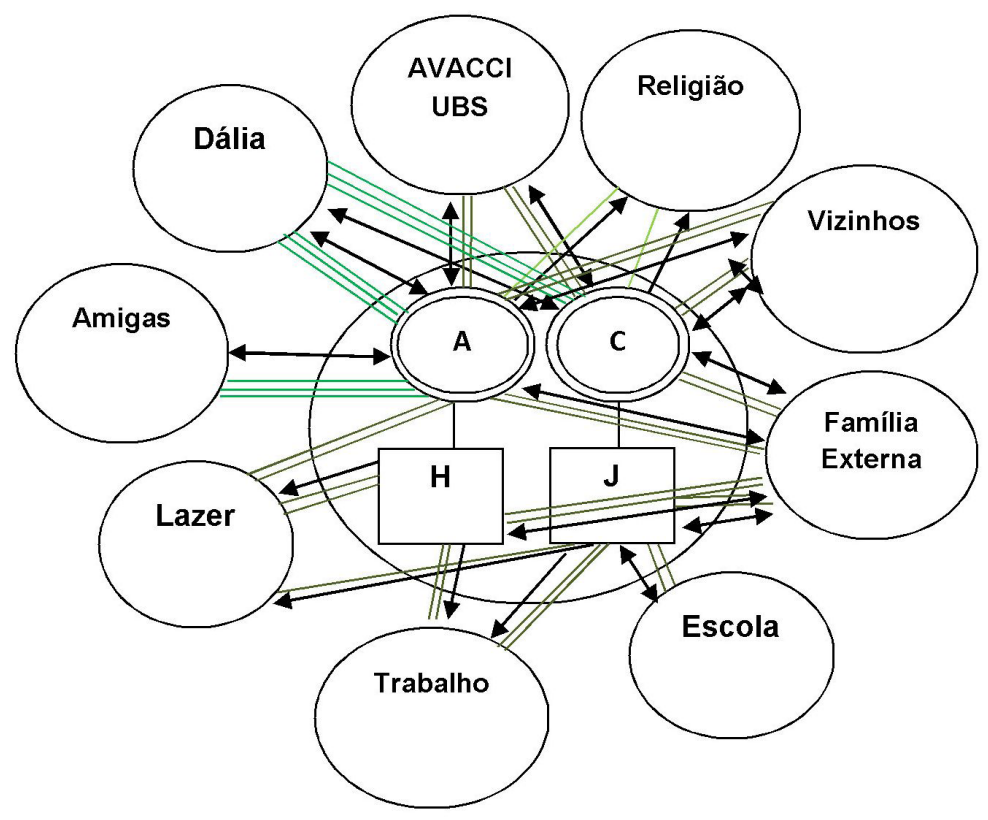

\begin{tabular}{|c|c|c|c|c|c|c|c|}
\hline \multicolumn{2}{|c|}{ LEGENDA } & \multirow[b]{2}{*}{ AVACCI } & \multirow[b]{2}{*}{$\begin{array}{l}\text { Associação de } \\
\text { Voluntariados no } \\
\text { Apoio ao } \\
\text { Combate ao } \\
\text { Câncer }\end{array}$} & \multirow{2}{*}{\begin{tabular}{|l|} 
A \\
C
\end{tabular}} & \multirow{2}{*}{$\begin{array}{l}\text { Araucária } \\
\text { Camélia }\end{array}$} & \multirow{2}{*}{$\begin{array}{l}\overline{ } \\
\bar{E}\end{array}$} & \multirow{2}{*}{$\begin{array}{l}\begin{array}{l}\text { Vínculo } \\
\text { moderado }\end{array} \\
\text { Vínculo } \\
\text { forte }\end{array}$} \\
\hline$\rightarrow$ & $\begin{array}{l}\text { Fluxo de } \\
\text { energia }\end{array}$ & & & & & & \\
\hline UBS & $\begin{array}{l}\text { Unidade } \\
\text { Básica de } \\
\text { Saúde }\end{array}$ & H & Hibisco & $\mathbf{J}$ & Jacinto & $\equiv$ & $\begin{array}{l}\text { Vínculo } \\
\text { muito forte }\end{array}$ \\
\hline
\end{tabular}

Figura 4 - Ecomapa da família 2. Divinópolis, 2014 
Em relação à religiosidade, Camélia diz ser Testemunha de Jeová e frequentar os cultos quinzenalmente, Araucária relatou ser católica, freqüenta as missas todos os domingos que não está viajando. Ao serem questionadas sobre o conceito de saúde e às mudanças ocorridas em sua vida, relataram que para elas saúde é ter disposição e animação para realizar todas as suas atividades, e ressaltaram ainda a importância da presença de familiares e amigos durante o seu tratamento, por meio do incentivo, apoio, carinho e solidariedade demonstrados.

\section{DISCUSSÃO}

As duas famílias eram de tipologias diferentes, a primeira era a peculiar família nuclear, representada pela mãe, pai e filhas, e a segunda estendida composta por duas irmãs e seus filhos únicos. Juntamente com o processo de adoecimento pelo câncer, surgem desafios a serem vivenciados pela pessoa e pela família. No decorrer da pesquisa, após buscar compreender o cotidiano vivenciado pelos familiares dessas mulheres que passaram por tratamento de câncer de mama e mastectomia, mas ainda estão em acompanhamento com uso de tamoxifeno, verificou-se que o tratamento, em especial a mastectomia total, causa um impacto não apenas para a mulher, mas estende-se no âmbito familiar, contexto social e grupo de amigos.

A doença afeta os relacionamentos interpessoais na família, visto que as alterações pela qual a mulher está passando tanto de ordem física, emocional e social se estendem aos familiares $^{(9)}$.

Geralmente, eles não estão preparados para enfrentar o adoecimento de um ente querido e para suportar a dor e o sofrimento de seu familiar, o que torna o sofrimento ainda maior. Nesta pesquisa, este quesito ficou claro para as pesquisadoras. O principal e de suma importância para a recuperação envolve a vivência familiar, mesmo que a dor sobressaia muitas vezes, o acompanhamento, o apoio e a cumplicidade fazem a diferença no resultado final do tratamento ${ }^{(10-11)}$. A família exerce um papel primordial na vida destas mulheres.

O vínculo se configura por intermédio das ligações afetivas e de proximidade que, na maioria das vezes, estão presentes nas demonstrações de carinho, afeto, sentimento de vontade de permanecerem juntos, admiração e respeito, que imprimem sensação de felicidade ${ }^{(9,12)}$, como foi encontrado de forma transparente pela família Um, na qual a harmonia está presente e transparece nos atos e nas falas de todos os membros.

Na família Dois, percebeu-se que Araucária e Camélia têm conflitos diários em relação ao estilo de vida diferente e aos afazeres domésticos, mas tem forte ligação afetiva entre si e com os familiares e, quando necessário, se apoiam e procuram a irmã Dália para auxiliar no gerenciamento de conflitos, visto que a irmã caçula representa para todos os familiares uma líder assertiva. Os vínculos afetivos podem também ser formados com quem não se tem laços consanguíneos, como é o caso de Araucária, que viaja pelo menos uma vez por mês com as amigas. Vale ressaltar que cada pessoa reage de forma diferente com a doença e que os vínculos não se estabelecem de forma igualitária.

A fundamental fonte de ajuda e apoio da pessoa que sofreu com o tratamento do câncer e está em acompanhamento são seus familiares, todavia a rede social, constituída por indivíduos que podem apoiar a pessoa, como os amigos e os vizinhos, é igualmente apontada como fundamental e imprescindível para suplantar as dificuldades ${ }^{(12-14)}$.

No caso da família de Araucária e Camélia, os profissionais devem saber que Dália constitui uma aliada importante e que necessita ser valorizada e instrumentalizada de maneira a agir de forma eficaz. Ela pode, por exemplo, ser orientada a supervisionar, mesmo que à distância, o relacionamento das irmãs e, incentivar Camélia a realizar alguma atividade de lazer e ter um convívio social maior. No caso de Margarida, o esposo Cravo e sua irmã Gardênia são os familiares que desenvolvem o papel de aliados dos profissionais de saúde.

Margarida conta também com outro auxílio, a fé e a crença na força divina. Estas têm importante papel no equilíbrio emocional, na aceitação das atividades, e proporcionam força para continuar a lutar e contribuir para o fortalecimento dos vínculos familiares ${ }^{(3,15)}$. Araucária e Camélia embora sejam religiosas não relataram a fé como aliado de aceitação e força.

A fé auxilia a pessoa a confiar em uma força superior e ajuda a manter a esperança(10) e, constitui uma forma de pensar construtiva, é um sentimento de confiança de que acontecerá sempre o melhor ${ }^{(1,10)}$. Efetivamente, a fé é um sentimento enraizado na nossa cultura e é tão indispensável quanto outras formas de 
enfrentamento ${ }^{(1,15)}$ de uma condição crônica.

As crenças, os valores, os comportamentos assimilados no convívio social conjecturam as experiências de vida que a pessoa e a família vão adquirindo no processo saúde/doença e no autocuidado(1). A partir desse pressuposto, o enfermeiro necessita compreender a família, acolhendo e reconhecendo suas experiências, a fim de mobilizar a investigação de novos conhecimentos e formas de aprendizagem para o exercício do cuidado com o familiar doente, destacando a importância das necessidades e prioridades da pessoa e de sua família, buscando qualificar e humanizar o atendimento prestado $^{(1,3,9)}$.

\section{CONSIDERAÇÕES FINAIS}

A avaliação familiar pautada no Modelo Calgary possibilitou conhecer as famílias e levantar os aspectos fundamentais da sua estrutura, desenvolvimento e funcionamento. Sabe-se que um dos grandes potenciais de atenção no domicílio é a capacidade de proporcionar suporte e de fortalecer as famílias, dentro das suas especificidades, para lidarem com circunstâncias críticas, como o câncer de mama, de forma a minimizar o sofrimento.

Os resultados deste estudo podem ser usados pelos enfermeiros para subsidiar o planejamento do trabalho no cuidado à mulher com câncer e sua família, possibilitando que auxilie a família na identificação de suas fragilidades e potencialidades.

Identificou-se que, a partir da avaliação integral da família, foi possível, em parceria com seus integrantes, propor intervenções de ajuda para a melhoria da qualidade de vida familiar, ajudando-a a vislumbrar suas próprias soluções para lidar com os problemas cotidianos.

A limitação deste estudo está relacionada ao método qualitativo que não permite generalização dos resultados ou estabelecimento de relações de causa e efeito.

A relevância do mesmo sustenta-se no fato de ter possibilitado compreender a vivência de todos integrantes da família da mulher mastectomizada, com base nas relações e sentimentos e a possibilidade de superação.
1. Radovanovic CAT, Cecilio HPM, Marcon SS. Avaliação estrutural, desenvolvimental e funcional da família de indivíduos com hipertensão arterial. Rev. Gaúch. Enferm.[Internet] 2013; 34(1) [acesso em 30 jan 2015].Disponível: http://seer.ufrgs.br/ index.php/RevistaGauchadeEnfermagem/article/ view/31893/24502

2. Silva L, Bousso RS, Galera SAF. Aplicação do Modelo Calgary para avaliação de famílias de idosos na prática clínica. Rev. Bras. Enferm. 2009; 62(4):530-4.

3. Cecilio HPM, Santos KS, Marcon SS. Modelo Calgary de avaliação da família: experiência em um projeto de extensão.Cogitare enferm. [Internet] 2014; 19(3) [acesso em 22 abr 2015]. Disponível: http://dx.doi.org/10.5380/ ce.v19i3.32729

4. Costa e Silva MED, Costa e Silva LD, Dantas ALB, Araújo DOR, Duarte IS, Sousa JFM. Assistência de enfermagem ao paciente oncológico no hospital. Rev. Enferm. UFPI. 2013; 2(n.esp):69-75.

5. Gozzo TO, Lopes RR, Prado MAS, Cruz LAP, Almeida AM. Informações para a elaboração de um manual educativo destinado às mulheres com câncer de mama. Esc. Anna Nery. 2012; 16(2):306-11.

6. Wright LM, Leahey M. Enfermeiras e famílias: um guia para avaliação e intervenção na família. $5^{a}$ ed. São Paulo: ROCA; 2012.

7. Sassá AH, Marcon SS. Avaliação de famílias de bebês nascidos com muito baixo peso durante o cuidado domiciliar. Texto Contexto Enferm. 2013; 22(2):442-51.

8.Yin RK. Estudo de caso: planejamento e métodos. $4^{\mathrm{a}}$ Ed. Porto Alegre: Bookman; 2010.

9. Dessen MA. Estudandoa família em desenvolvimento: desafios conceituais e teóricos. Psicol. cienc. prof. 2010; 30(n.esp.):202-19.

10. Guerrero GP, Zago MMF, Sawada NO, Pinto MH. Relação entre espiritualidade e câncer: perspectiva do paciente. Rev. Bras. Enferm. 2011; 64(1):53-9.

11. Palmieri BN, Moulatlet EM, Buschinelli LKO, Pinto-eSilva MEM. Aceitação de preparações e sua associação com os sintomas decorrentes do tratamento de câncer em pacientes de uma clínica especializada. Cad. Saúde Colet. 2013; 21(1):2-9.

12. Hubbard G, Menzies S, Flynn P, Adams S, Haseen F, Thomas I, et al. Relational mechanisms and psychological outcomes in couples affected by breast cancer: a systematic narrative analysis of the literature. BMJ Support Palliat Care. 2013; 3(3):309-17.

13. Santos DB, Vieira EM. Imagem corporal de mulheres com câncer de mama: uma revisão sistemática da literatura. Ciênc. Saúde Colet. 2011; 16(5):2511-22. 
14. Metcalfe KA, Quan ML, Eisen A, Cil T, Sun P, Narod $\mathrm{SA}$. The impact of having a sister diagnosed with breast cancer on cancer-related distress and breast cancer risk perception. Cancer. 2013; 119(9):1722-8.

15. Lim JW, Ashing-Giwa KT. Is family functioning and communication associated with health-related quality of life for Chinese- and Korean-American breast cancer survivors? Qual Life Res. 2013; 22(6):1319-29. 